\title{
Function and mechanism of F-box proteins in gastric cancer (Review)
}

\author{
JIAN GONG, JUAN CAO, GUINAN LIU and JI-RONG HUO \\ Department of Gastroenterology, The Second Xiangya Hospital, \\ Central South University, Changsha, Hunan 410011, P.R. China
}

Received March 9, 2015; Accepted April 24, 2015

DOI: $10.3892 /$ ijo.2015.2983

\begin{abstract}
Gastric cancer (GC) is one of the commonest cancers with high mortality. Despite improvement in early detection and treatments, the outcome of advanced GC remains unsatisfactory due to the poor understanding of the intricate pathogenesis of GC. GC is a multifactorial and multistep disease which involves activation of oncogenes and inactivation of tumor suppressor genes. Ubiquitin proteasome system (UPS) catalyzing many critical protein substrates is involved in initiation and development of cancer. F-box proteins (FBPs) are the main functional components of UPS. Accumulated evidence strongly suggests that abnormal regulations of FBPs contribute to uncontrolled proliferation, genomic instability and cancer. In this review, we discuss how the dysregulated FBPs promote the occurrence and development of GC.
\end{abstract}

\section{Contents}

1. Introduction

2. The characteristics of ubiquitination

3. FBPs as oncogenes SKP2, FBXO6 and FBXO32 in GC

4. FBPs as tumor suppressor genes FBXW7, $\beta$-TrCP, FBXL5 and $\mathrm{FBXO} 31$ in GC

5. Conclusion and future direction

\section{Introduction}

GC is the fourth most commonly diagnosed malignancy and the second leading cause of cancer-related death with a total of 989,600 new stomach cancer cases and 738,000 deaths

Correspondence to: Professor Ji-Rong Huo, Department of Gastroenterology, The Second Xiangya Hospital, Central South University, 139 Middle Renmin Road, Changsha, Hunan 410011, P.R. China E-mail: huojir008@126.com

Key words: gastric cancer, F-box protein, ubiquitin-proteasome system, E3 ubiquitin ligase according to global cancer statistics (1). Surgery is the dominant treatment of GC, however, $>80 \%$ of diagnoses occur at the middle to late stage of the disease and some of the patients miss the opportunity for surgery $(2,3)$, thus highlighting an urgent need for novel biomarkers and improved therapies. Multiple studies have shown that GC is the outcome of missregulation of many related genes including oncogenes and tumor suppressor genes (4). Accumulating data strongly suggest that deregulation of FBPs, which mediates the degradation of many regulatory proteins, contributes to the initiation and promotion of cancer. In this review, we summarize the literature on the FBPs involved in GC, focusing on the function and mechanism of each related F-box protein (FBP) in GC.

\section{The characteristics of ubiquitination}

Cellular proteins are in a constant state of flux. Protein degradation is essential for the removal of excessive proteins. Two major protein degradation systems exist in cells, the authophagy-lysosome and UPS. Approximately $80-90 \%$ of intracellular proteins are degraded though UPS. Ubiquitination is a process in which ubiquitin moieties are covalently attached to a substrate through an enzymatic cascade. The proteasome and deubiquitinases (DUBs) are essential components of this system. Depending on ubiquitin-ubiquitin linkage, polyubiquitinated proteins can either be activated through K63 linkage, or recognized and degraded by the $26 \mathrm{~S}$ proteasome (through K48 linkage). Formation of a ubiquitin Lys 48 chain on the $\varepsilon-\mathrm{NH} 2$ group of a substrate internal Lys residue (polyubiquitination) can target the substrate for degradation by the $26 \mathrm{~S}$ proteasome in an ATP-dependent manner (Fig. 1).

Ubiquitin enzymes. UPS serves as a powerful regulatory mechanism in proteolytic pathways (5). The UPS exerts its functions mainly through the concerted efforts of a group of enzymes. Human genome encodes 2 E1s, 38 E2s and $>600 \mathrm{E} 3 \mathrm{~s}$, consistent with their role in the ultimate selection of substrates (6). The role of E1 enzymes in cancers has not been fully studied yet, and only a few reports have focused on E2 enzymes. However, more and more evidence strongly suggests a link between E3 enzymes and cancer development. Crucially, E3 ligases determine the substrate specificity for ubiquitylation and subsequent degradation. Based on the specific structural motifs they contain, we can classify 


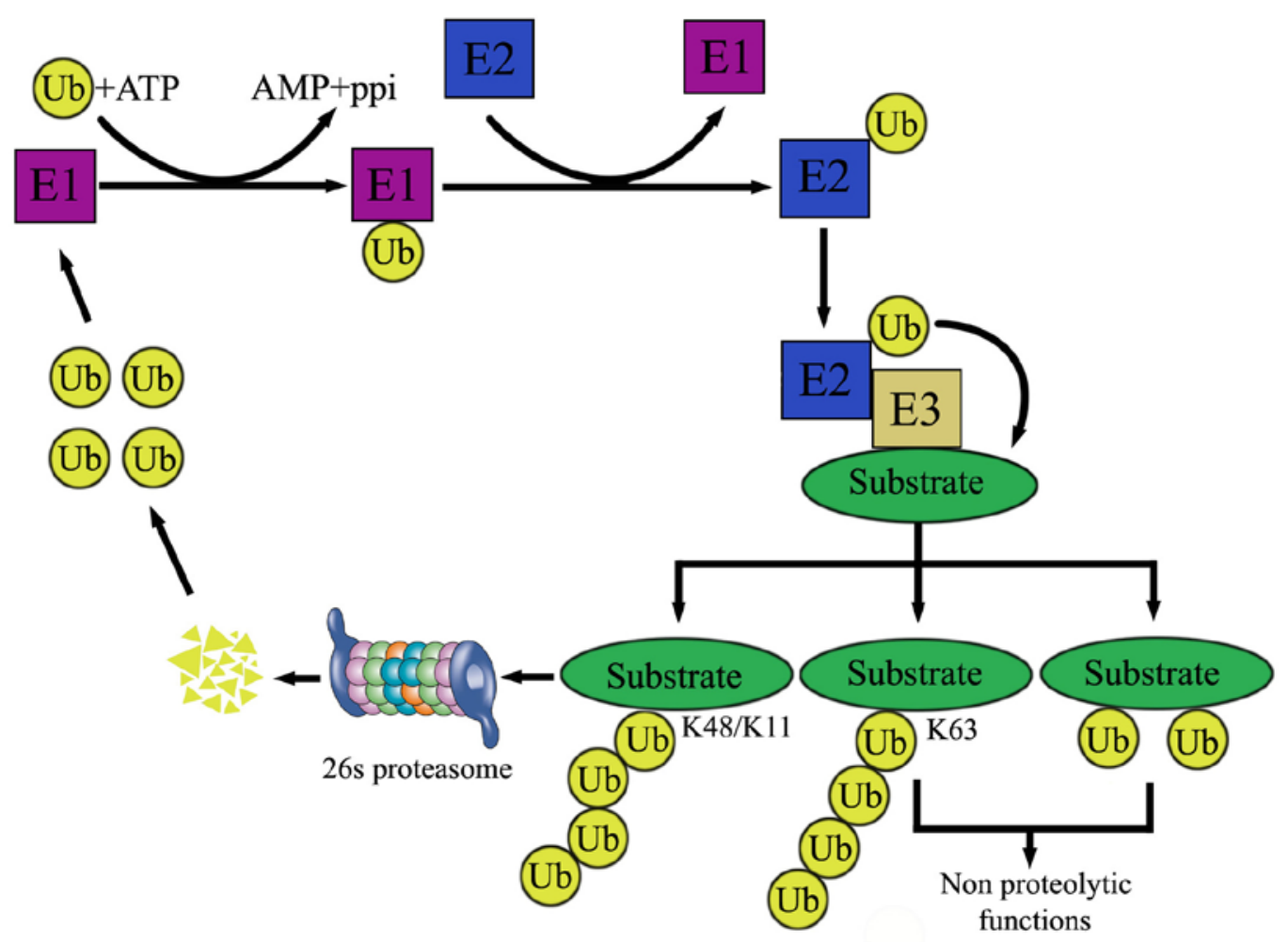

Figure 1. Ubiquitin pathways in the regulation of protein degradation. Ubiquitin is first attached to E1 ubiquitin-activating enzyme in the presence of ATP. The activated ubiquitin is then transferred to E2 ubiquitin-conjugating enzyme. E3 ubiquitin ligase recognizes a protein substrate, recruits an E2-ubiquitin complex, and catalyzes ubiquitin transfer from E2 to substrate. A single run of the reaction causes monoubiquitination of a target protein that could change its function, whereas multiple runs of the reaction lead to polyubiquitination of the substrate. Depending on ubiquitin-ubiquitin linkage, polyubiquitinated proteins can either be activated (through K63 linkage), or recognized and degraded by the 26S proteasome (through K48 linkage).

E3 ligases into 4 major classes (Fig. 2): the N-end rule E3s (homologous E6 associated protein carboxyl terminus) HECT-E3s (really interesting new finger) RING-E3s, and APC/C E3s. RING-E3s can further be subdivided into RINGcontaining single peptide E3s, Cullin-RING ligases (CRLs) and their derivatives, U-box E3s (6). CRLs is the largest family of RING-E3s, which contains 8 members: namely, CRL1, CRL2, CRL3, CRL4A, CRL4B, CRL5, CRL7 and CRL9 (7). The best characterized CRLs family E3s is Skp1-Cullin-F-box (SCF) complex $(8,9)$. SCF complex consists of four structural and functional components: Skp1 (adaptor protein), Cul1 (scaffold protein), ROC1/Rbx1 (RING protein), and F-box protein (Fig. 3), the latter serves as a receptor for target proteins. F-box proteins (FBPs) play a fundamental role in the proper functioning of E3 ligases.

The ubiquitin proteasome pathway. Ubiquitin attachment to substrates is accomplished by the coordinated activity of three enzymes (Fig. 1): ubiquitin-activating enzyme (E1), ubiquitin conjugating enzyme (E2) and ubiquitin-protein ligase (E3). The degradation of proteins by the UPS is mainly comprised of two steps. The first step is linking a ubiquitin molecule to E1 via a high-energy thiol ester at carboxyl terminal glycine residue in an ATP and $\mathrm{Mg}^{2+}$-dependent manner. Next, E2 accepts the activated ubiquitin molecule from E1 and with help from an E3 ubiquitin ligase-transfers it to the lysine residue of a target protein. Then the ubiquitin proteins are recognized and degraded by 26 proteasomes to several small peptides.
The F-box protein families. F-box is a widespread protein motif of $\sim 40-50$ amino acids and it functions as a site of protein-protein interaction. FBPs can be organized into three categories on the basis of the presence of recognizable domains beyond the F-box domain, those with WD 40 repeats (FBXW), leucine-rich repeats (FBXL), or other domain-containing proteins (FBXO) (10). In humans, 69 FBPs have been identified so far. The FBXW family is composed of 10 proteins, all members containing WD40 repeat domains. FBXL family donates each protein group harboring an F-box and leucine-rich domains, comprising 22 proteins. The remaining 37 F-box proteins were named FBXO family (Fig. 2). FBXO is an abbreviation for F-box and other domains. These F-box proteins often have conserved homology domains that were either recognized or are not present in a large number of F-box proteins. Currently, emerging experimental and clinical data has begun to reveal some interesting biological functions on FBXO proteins. The abnormal activation of F-box proteins were found in many human cancers, but the underlying mechanism was not completely clarified. Below we discuss each related F-box protein, including its targeting substrates and affected biologic processes in GC.

\section{FBPs as oncogenes SKP2, FBXO6 and FBXO32 in GC}

FBPs exert antitumoral or promoting effect depending on the specific substrates they degrade. FBPs function as oncoproteins when overexpressed if their substrates are tumor suppressors or as tumor suppressors if their substrates are oncoproteins. 


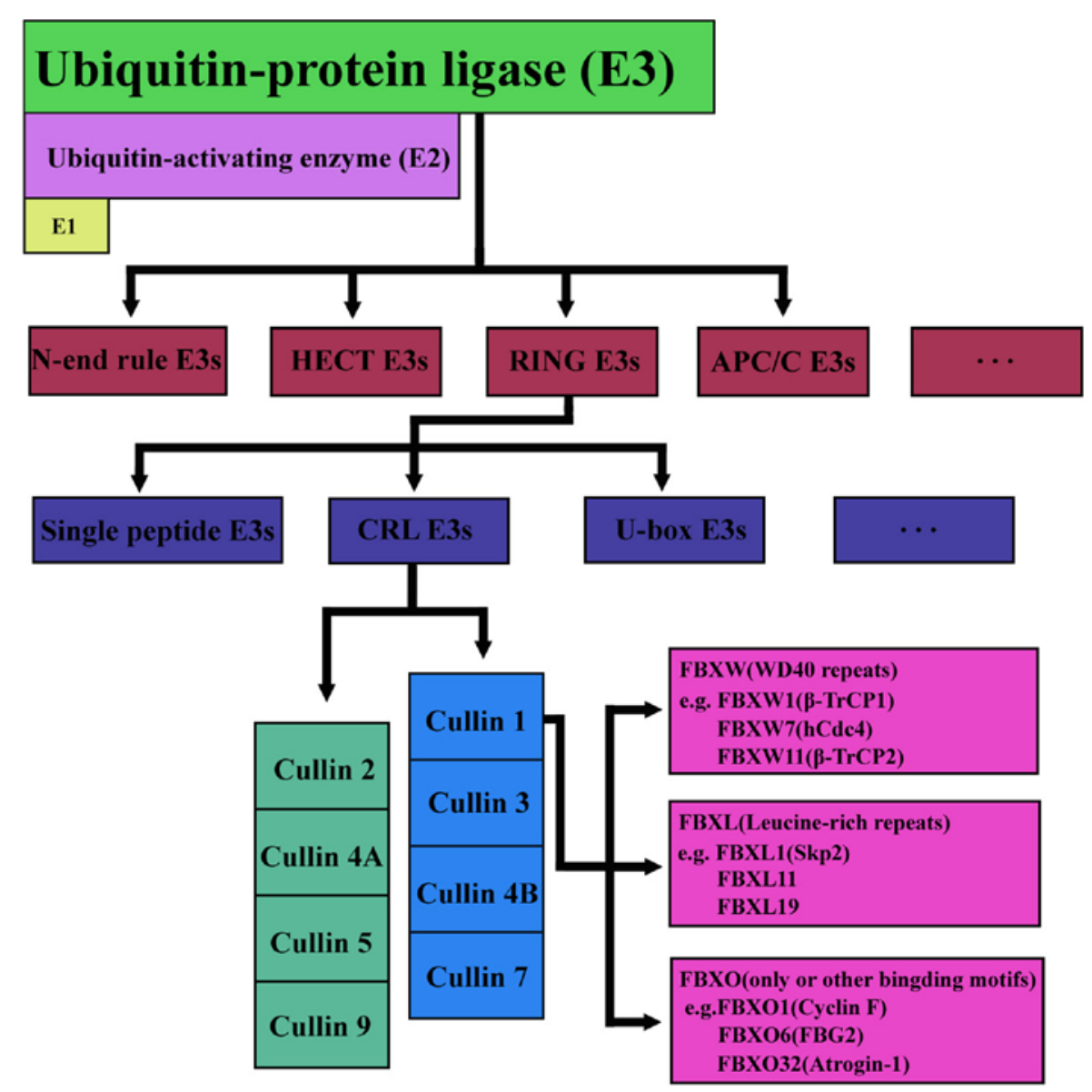

Figure 2. Major classes of E3 ubiquitin ligase and FBPs. E3 ubiquitin ligase can be classified into 4 major classes: the N-end rule E3s, HECT-E3s, RING-E3s and APC/C E3s. RING-E3s can further be subdivided into RING-containing single peptide E3s, CRL and its derivatives, U-box E3s. CRLs is the largest family of RING-E3s, which contains eight members: namely, CRL1, CRL2, CRL3, CRL4A, CRL4B, CRL5, CRL7 and CRL9. FBPs can be categorized into three subclasses, FBXW, FBXL and FBXO family proteins.

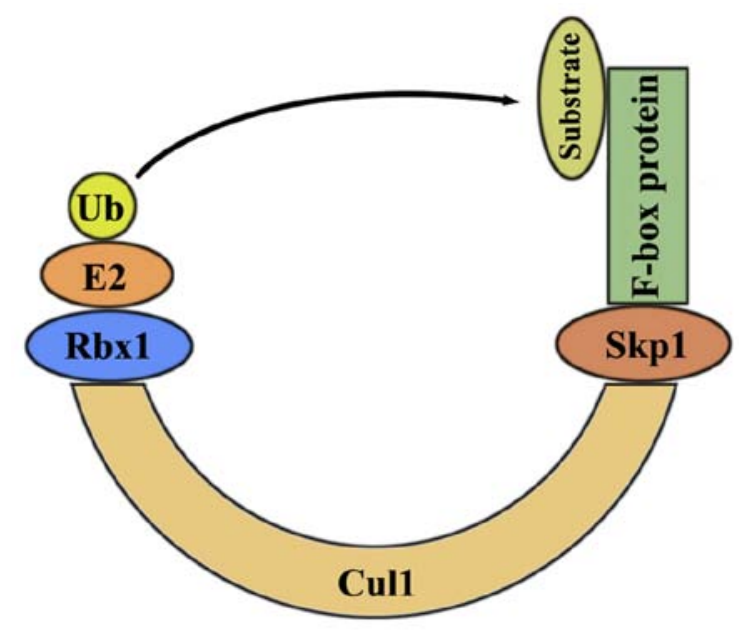

Figure 3. Structure of SCF type E3 ubiquitin ligase. The SCF type E3 ubiquitin ligase consists of four components: an adaptor subunit (Skp1), a RING-domain protein (RbX1), a scaffold protein (Cullin1) and a variable subunit denoted as FBP that binds the substrate.

A FBP has more than one substrate, for the same reason, one substrate can be degraded by different FBPs. Three FBPs (SKP2, FBXO6 and FBXO32) have shown potential oncogenic role in $\mathrm{GC}$.

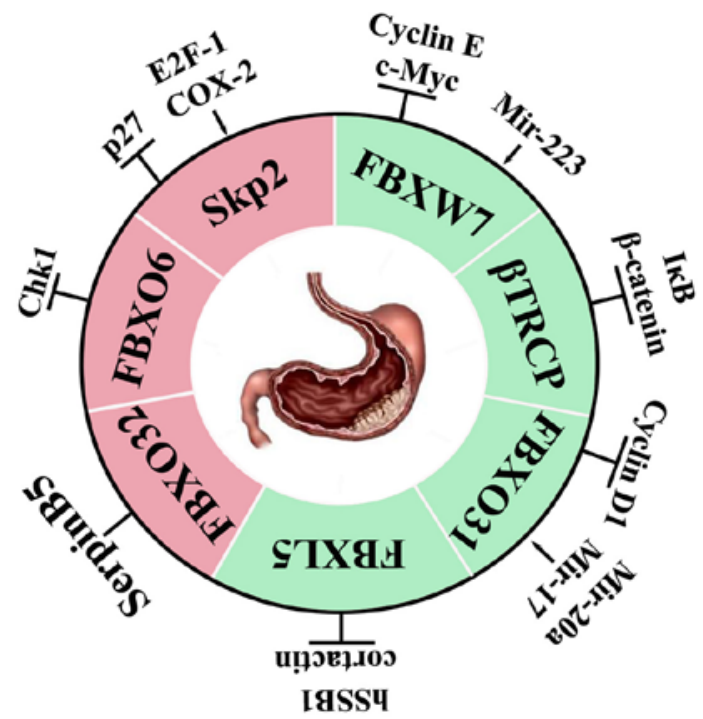

Figure 4. Illustration of the main FBPs and its major upstream or downstream targets in GC. SKP2, FBXO6 and FBXO32 are potential oncogenes in GC (red background). FBXW7, $\beta$-TrCP, FBXL5 and FBXO31 are potential downstream suppressor genes in GC (green background). P27, Chk1, hSSB1, cortactin, Cyclin D1, I KB, $\beta$-catenin, Cyclin, E c-Myc are the specific or potential downstream substrates of its corresponding F-box protein. SerpinB5 is interacting protein of FBXO32. MiR-20a, miR-17, mir-223, E2F-1, COX-2 are the potential upstream regulators of its corresponding F-box protein. 
SKP2. SKP2 was characterized as an Skp1-binding protein to regulate cell cycle progression through ubiquitin mediated proteolysis (11). It is regulated by a network of proteins including cyclins, cyclin-dependent kinases (CDKs) (12) and CDK inhibitors (CKIs) (13). Burgeoning amounts of literature strongly implies that SKP2 plays an oncogenic role in human cancers. Firstly, SKP2 was found to be frequently overexpressed in various human cancers (14-17) and it was associated with poor prognosis as well as tumor metastasis (18). Secondly, most of its downstream substrates were tumor suppressor proteins including p27 and p21 (19). Thirdly, SKP2 acetylation could promote its oncogenic function by regulating the downstream targets such as p21 and FOXO1, and upregulated the acetylation of SKP2 promoted cell growth $(20,21)$. Fourthly, SKP2 genes were associated with the increased cell cytotoxicity induced by drugs like platinum (22). Recently, research has shown that SKP2 predicts poor prognosis and maintains a cancer stem cell pool (23-25). Moreover, SKP2 has been proven to be linked with radiotherapy and chemotherapy resistance $(26,27)$. Collectively, these studies suggest that SKP2 may be an ideal therapeutic target for human cancer.

In a study of 98 cases of human GC, it was found that overexpression of SKP2 at the mRNA level was associated with poor OS (28). The overexpression of SKP2 in gastric carcinoma cells decreased the level of $\mathrm{p} 27$, increased cell growth rate, rendered cancer cells more resistant to actinomycin D-induced apoptosis and increased their invasion potential (28). SKP2 protein was proved to be negatively associated with p27 in gastric carcinoma and was positively associated with differentiation degree, vessel invasion and lymph node metastasis (29). Other regulators of SKP2 also exist. COX-2 contributed to the expression of SKP2 and poor survival in human gastric carcinomas (30). E2F-1 reversed the multidrug resistance by downregulating the expression of SKP2 in gastric cell line SGC7901 (31). Mechanistic investigation using the in vitro cell culture models was performed to validate the critical role of SKP2-p27 axis in the growth and invasion of SGC7901. E2F-1 is one of DNA-binding protein in E2F family (E2F-1 to E2F-6), and it has the potential to function as an oncogene (32). Wei et al (33) discovered that the knockdown of SKP2 expression suppressed the ability of GC cell line MGC803 to form tumors and to metastasize to the lungs of mice. In contrast, overexpression of Skp2 promoted tumorigenesis of GC in mice.

Helicobacter pylori, one of the most important pathogenic factors in noncardia GC, was associated with low expression of p27 protein in human gastric epithelial cells, which might lead to increased gastric epithelial cell proliferation, decreased apoptosis and increased risk for GC (34). Kim et al (35) also found a reciprocal relationship between increased p27 and decreased SKP2 protein expression following the eradication of helicobacter pylori in chronic gastritis patients. Rosiglitazone, a peroxisome proliferator-activated receptor gamma, attenuated SKP2 expression and promoted p27 accumulation in helicobacter pylori infected human gastric epithelial cells (36). The specific mechanism of helicobacter pylori in GC is still not clear. The above research provides a possible mechanism of helicobacter pylori resulting in GC.

FBXO6. Proper post-translational modification of the substrates are often required for their interaction with respec- tive FBPs (37). The old paradigm of phosphorylation-directed substrate recognition by FBPs may still be dominant, but it is no longer absolute. FBXO6 can recognize degrons that are modified by glycosylation or the addition of mannose oligosaccharides. For instance, FBXO6 binds to a glycosylated degron in T cell receptor $\alpha$-chain 17. FBXO6, also named Fbs2, is involved in the endoplasmic reticulum-associated degradation (ERAD) pathway by mediating the ubiquitination of glycoproteins (38). FBXO6 transcript is widely expressed in various tissues (39), which was reported to be involved in neuroblastoma tumorigenesis (40). Merry et al (41) showed an inverse correlation of FBXO6 and Chk1 protein in breast tumor tissues, and the low expression of FBXO6 causing Chk1 accumulation increases tumor cells resistance to chemotherapy drug irinotecan. Chk1 is a key protein kinase in the replication checkpoint. FBXO6 mediates the Chk1 ubiquitination and degradation, thus terminating the checkpoint (42). Inhibition of FBXO6 gene expression increased the biological effects of cadmium toxicity (43). Zhang et al (44) reported that FBXO6 accelerated the growth and proliferation of GC cells and normal gastric cells. These findings shed new light on the tumor-promoting role of FBXO6. However, FBXO6 did not affect apoptosis and invasion of GC cells or normal gastric cells. One of the possible explanation is that FBXO6 has little influence on the key genes concerned with apoptosis and invasion. FBXO6 might exert many functions of cells with other FBPs participating in the metabolism, underscoring the need for further studies aimed at clarifying the specific role of FBXO6 in GC.

FBXO32. The FBXO32 gene was first discovered by Gomes et al (45) and named atrogin-1. They demonstrated an increase of FBXO32 mRNA during muscle atrophy. Patients with neoplastic disease always develop cachexia eventually. In human cancer cachexia, a significant increase in FBXO32 mRNA levels may occur with greater rates of weight loss. However, pharmacological correction between muscle wasting and FBXO32 expression in cancer cachexia is not always tightly coupled $(46,47)$. D'Orlando et al $(48)$ studied 38 gastric adenocarcinoma cancer patients and 12 controls. The expression of atrophy-related genes FBXO32 in rectus abdominis muscle is not always affected by the presence of cancer, the disease stage, or the severity of weight loss. Consistent with this result, Bonetto et al (49) did not find an increase of FBXO32 mRNA levels in GC patients than control groups. Mammary serine protease inhibitor B5 (SerpinB5) is a $42-\mathrm{kDa}$ protein, and functions as a tumor suppressor in breast cancer (50). SerpinB5 is believed to be a potential oncogene in GC and FBXO32 is one of SerpinB5-interacting proteins (51). Whether the expression of FBXO32 in rectus abdominis muscle can be used as a signal for muscle atrophy also needs further extensive research. Progress on identification and characterization of specific endogenous FBXO32 substrates is lacking.

\section{FBPs as tumor suppressor genes FBXW7, $\beta$-TrCP, FBXL5 and FBXO31 in gastric cancer}

Numerous FBPs including FBXW7, $\beta$-TrCP, FBXL5 and FBXO31, have been shown to be tumor suppressors in GC. 
Frequent inactivating mutations or downregulated expression of these E3 ubiquitin ligases have been detected in GC. Besides mutation and gene copy loss, epigenetic alteration also contributed to inactivation of these tumor suppressors. FBPs with tumor suppressor activity in GC are discussed in detail below.

FBXW7 FBXW7, another well-studied F-box protein, was first identified in budding yeast in 1973 (52). FBXW7 genes locate at chromosome 4 (4q31.3), and it consists of 1 specific exon and 10 common exons. Human FBXW7 encodes 3 transcripts FBXW7 $\alpha$, FBXW7 $\beta$ and FBXW7 $\gamma$ (53). All the 3 isoforms contain conserved interaction domains in the C-terminus and various isoform-specific domains in the $\mathrm{N}$-terminal region (54). Each isoform is differentially regulated both in tissue expression and cellular location. FBXW7 $\alpha$ is ubiquitously expressed in all murine tissues, while FBXW7 $\beta$ is restricted to brain and testis and FBXW7 $\gamma$ to heart and skeletal muscles (55). FBXW7 $\alpha$ is thought to perform most FBXW7 functions. The localization of each isoform also varies within the cell and is located in distinct subcellular compartments. FBXW $7 \alpha, \beta$ and $\gamma$ isoforms localize to the nucleoplasm, cytoplasm and nucleolus, respectively (56). Rapidly accumulating data show that FBXW7 exerts its antitumor function primarily by promoting the degradation of some crucial oncoproteins including cyclin E (57), c-Myc (58), c-Jun (59), Notch (59), presenilin (60), Mcl-1 (myeloid cell leukemia) (61) with one exception being the tumor suppressor NF1 (neurofibromatosis type 1) (62). Recent progress in many other new substrates has deepened our understanding of the diverse oncogenic pathways that FBXW7 regulates (63-66). Furthermore, large-scale cancer genome studies have shown that FBXW7 is among the most mutated cancer genes $(67,68)$. Mouse models provided new insights into how FBXW7 mutations led to carcinomas (69-71).

FBXW7 has been implicated as a tumor suppressor gene in various tumors. Frequent inactivation of FBXW7 by deletions or point mutations occurs in cancers. It is found that hCDC4 mutations exist not only in early, but also advanced GC. In agreement, the study by Milne et al showed similar results (72). Yokobori et al (73) for the first time revealed the relationship between low expression of FBXW7 and other tumor suppressor genes. Their results showed that both p53 mutation and low FBXW7 expression were correlated with poor prognosis in clinical GC cases. FBXW7 was demonstrated to be regulated by miRNA. miR-223 in GC cell line SGC7901 were able to decrease FBXW7 mRNA expression and reduced cellular apoptosis and increased proliferation and invasion in vitro (74). Eto et al (75) reported that miR-223/FBXW7 pathway affected the GC sensitivity to the biological targeted drug trastuzumab.

$\beta$-TrCP. Human $\beta$-TrCP, was first identified in 1998 as a binding partner of HIV-1 Vpu protein in a yeast two-hybrid screening. The role of $\beta$-TrCP in cancers is tissue-dependent. $\beta$-TrCP mainly acts as an oncoprotein, but in some situations as a tumor suppressor, depending on the function of the targeted substrates. Two main substrates of $\beta$-TrCP are I $\mathrm{B}$ in the $\mathrm{NF}-\kappa \mathrm{B}$ pathway and $\beta$-catenin in Wnt pathway $(76,77)$. $\mathrm{I} \kappa \mathrm{B}$, inhibitor of $\mathrm{NF}-\kappa \mathrm{B}$, functions as a tumor suppressor. $\beta$-catenin has been identified to be upregulated in various types of human cancer, and is always correlated with poor prognosis and short survival $(78,79)$. I $\kappa \mathrm{B}$ and $\beta$-catenin exert antagonistic functions, thus making it hard for them to be ideal drug targets. The development of $\beta$-TrCP inhibitors might be a feasible therapeutic approach for $\mathrm{NF}-\kappa \mathrm{B}$-associated human disease. $\beta$-TrCP also participates in cell adhesion and migration (80). $\beta$-TrCP is a member of the SCF family with both oncogenic and tumor suppressor properties. Taken together, $\beta$-TrCP might have a greater role as an oncogenic protein than as a tumor suppressor in cancer.

There are very few studies on the function of $\beta$-TRCP in GC. Saitoh and Katoh (81) reported that $\beta$-TRCP2 was found to be the major $\beta$-TRCP expressed in GC. $\beta$-TRCP1 was expressed in several GC cell lines, but not in any case of primary GC. $\beta$-TRCP2 was expressed in most cases of primary $\mathrm{GC}$ at almost the equal level in tumor and in non-cancerous portion of gastric mucosa. An analysis of somatic mutations in 95 GC specimens found 5 missense mutations in $\beta$-TRCP2, and in these particular tissues, with oncogene $\beta$-catenin level higher than controls which means that $\beta$-TrCP2 may function as a tumor suppressor in GC (82).

FBXL5. Most examples of F-box protein degradation are linked to the cell cycle, but the regulation of FBXL5 is unique in this regard. SKP1-CUL1-FBXL5 mediates the degradation of iron regulatory protein 2 (IRP2) under conditions of high iron levels in eukaryotic cells $(83,84)$. IRP2 is a key event for the maintenance of an appropriate intracellular concentration of iron. Liver-specific deletion of FBXL5 resulted in deregulation of both hepatic and systemic iron homeostasis, leading to the development of steatohepatitis (85). Gradually, the role of FBXL5 in cancer is being clarified. Dragoi et al (86) demonstrated that depletion of FBXL5 did not alter the level of E-cadherin mRNA significantly but increased E-cadherin protein level. These results suggested that FBXL5 affected E-cadherin expression at the post-transcriptional level. FBXL5 was associated with epithelial-to-mesenchymal transition (EMT) and metastatic prowess. FBXL5 negatively modulated human single-strand DNA binding protein 1 (hSSB1) for destruction to regulate DNA damage response in lung cancer cell lines and clinical lung cancer samples (87). FBXL5 overexpression in GC cells mediated the ubiquitination and degradation of cortactin (88). Cortactin was proved to be involved in the regulation of cell migration and cell-cell junction (89) and was reported to increase cancer cells migration and invasion (90). Further studies are required to reveal the exact molecular mechanisms and signaling pathways through which FBXL5 modulates GC cell migration and invasion.

FBXO31. FBXO31, is located in chromosome 16q24.3, and plays a crucial role in DNA damage response $(91,92)$, neuronal morphogenesis (93) and tumorigenesis (94-97). FBXO31 was first identified as a candidate tumor suppressor in breast cancer (97). A well-characterized substrate of FBXO31 is cyclin D1, which was identified in melanoma cell line SK-MEL-28 (91). However, a study from Kogo et al showed conflicting results in esophageal squamous cell carcinoma (ESCC) (95). They found that the expression level of FBXO31 was positively associated with tumor invasion depth and clinical stage. They revealed concordant expression rather than inverse correlation between cyclin D1 and FBXO31 in ESCC cells, which indicated that 
cyclin D1 was not a candidate substrate in ESCC. Therefore, the expression and function of FBXO31 is still controversial. In this context, Zhang et al (96) detected the expression of FBXO31 in GC. They demonstrated that the expression of FBXO31 was significantly decreased in GC (82/90) and the decreased expression of FBXO31 was associated with tumor size, tumor infiltration, clinical grade and patients' prognosis in GC. Furthermore, Zhang et al (96) found that FBXO31 could inhibit colony formation and induces G1 phase arrest in GC cells possibly by targeting cyclin D1 through the ubiquitinproteasome pathway. This result is consistent with Santra et al (91). Furthermore, overexpression of FBXO31 dramatically inhibited xenograft tumor growth in nude mice. Zhang et al (96) highlighted the regulatory mechanism of miRNAs to FBXO31, they first revealed that the increased expression of miR-20a and miR-17 in GC inhibited the expression of FBXO31. In spite of all the work on FBXO31, the expression profile, clinical significance, biological functions and the regulation mechanism of FBXO31 in different cancers is still unclear. It is necessary to investigate other mechanism, such as DNA methylation, loss of heterozygosity $(\mathrm{LOH})$ contributing to the downregulation in GC tissue.

\section{Conclusion and future direction}

The UPS is an important mechanism regulating protein degradation. Extensive study of UPS has led to a better understanding of the molecular mechanism by which E3 ligases regulate cellular processes and of how their deregulations contribute to GC. FBPs, as the main component of E3 ligases, have a critical role in digestive system cancers (10). Substantial current research is focused on identifying new FBPs and the substrates that binds to each FBP. Only PBPs, SKP2, FBXW7 and $\beta$ TRCP, showed strong clinical relevance by virtue of its ability to regulate key substrates in the initiation and development of $\mathrm{GC}$, but more research is needed to apply the results to clinic. According to our experimental results, the expression of FBXO31 in ESCC has been proved to be related to drug resistance in vitro. Therefore, FBPs have great potential as biomarkers to monitor clinical indexes.

However, all the current discovered functions are just the tip of the iceberg and the range of the FBP-dependent processes will increase. SKP2, the authentic oncoprotein, has shown to be involved in helicobacter pylori related chronic gastritis. However, whether patients with FBXW7 mutation are more likely to be infected with helicobacter pylori is still unknown. FBXL5, FBXO6, FBXO31 and FBXO32 have begun to show their roles in participation in the initiation and progression of GC. Unfortunately, the specific roles of these proteins in GC still need to be further investigated. Future study will be directed to functional characterization of all 69 F-box proteins and their corresponding substrates to thoroughly elucidate the biological processes in GC. Here we have provided a useful conceptual framework for understanding the complex FBPs related to GC (Fig. 4). The recent therapeutic success of the proteasome inhibitor bortezomib has expedited the efforts to develop inhibitors of other components in the UPS. FBPs, such as those described in this review, are promising targets or biomarkers for GC in theory, however, FBPs suffers from several challenges. For example, one F-box protein can promote the degradation of either oncogenes or tumor suppressor genes at the same cell, the therapeutic outcome of inhibitors has to be cell context-dependent. Therefore, a better mechanistic understanding of the many uncharacterized FBPs both with regard to their substrates and the posttranslational modifications will be a hotpot of future research.

\section{Acknowledgements}

J.G. and J.-R.H. are grateful to the Fundamental Research Funds for the Central Universities of Central South University (No. 2015zzts119).

\section{References}

1. Jemal A, Bray F, Center MM, Ferlay J, Ward E and Forman D: Global cancer statistics. CA Cancer J Clin 61: 69-90, 2011.

2. Zheng L, Wu C, Xi P, Zhu M, Zhang L, Chen S, Li X, Gu J and Zheng Y: The survival and the long-term trends of patients with gastric cancer in Shanghai, China. BMC Cancer 14: 300, 2014.

3. Liu HS and Xiao HS: MicroRNAs as potential biomarkers for gastric cancer. World J Gastroenterol 20: 12007-12017, 2014.

4. Yakirevich E and Resnick MB: Pathology of gastric cancer and its precursor lesions. Gastroenterol Clin North Am 42: 261-284, 2013.

5. Yen H-CS, Xu Q, Chou DM, Zhao Z and Elledge SJ: Global protein stability profiling in mammalian cells. Science 322: 918-923, 2008.

6. Zhao Y and Sun Y: Cullin-RING Ligases as attractive anticancer targets. Curr Pharm Des 19: 3215-3225, 2013.

7. Deshaies RJ and Joazeiro CA: RING domain E3 ubiquitin ligases. Annu Rev Biochem 78: 399-434, 2009.

8. Reed SI: Ratchets and clocks: The cell cycle, ubiquitylation and protein turnover. Nat Rev Mol Cell Biol 4: 855-864, 2003.

9. Peters J-M: The anaphase promoting complex/cyclosome: A machine designed to destroy. Nat Rev Mol Cell Biol 7: 644-656, 2006.

10. Gong J, Lv L and Huo J: Roles of F-box proteins in human digestive system tumors (Review). Int J Oncol 45: 2199-2207, 2014.

11. Bai C, Sen P, Hofmann K, Ma L, Goebl M, Harper JW and Elledge SJ: SKP1 connects cell cycle regulators to the ubiquitin proteolysis machinery through a novel motif, the F-box. Cell 86: 263-274, 1996.

12. Morgan DO: Principles of CDK regulation. Nature 374: 131-134, 1995.

13. Sherr CJ and Roberts JM: Inhibitors of mammalian G1 cyclindependent kinases. Genes Dev 9: 1149-1163, 1995.

14. Hershko D, Bornstein G, Ben-Izhak O, Carrano A, Pagano M, Krausz MM and Hershko A: Inverse relation between levels of p27(Kip1) and of its ubiquitin ligase subunit Skp2 in colorectal carcinomas. Cancer 91: 1745-1751, 2001.

15. Fukuchi M, Masuda N, Nakajima M, Fukai Y, Miyazaki T, Kato $\mathrm{H}$ and Kuwano $\mathrm{H}$ : Inverse correlation between expression levels of p27 and the ubiquitin ligase subunit Skp2 in early esophageal squamous cell carcinoma. Anticancer Res 24B: 777-783, 2004.

16. Yang G, Ayala G, De Marzo A, Tian W, Frolov A, Wheeler TM, Thompson TC and Harper JW: Elevated Skp2 protein expression in human prostate cancer: Association with loss of the cyclindependent kinase inhibitor p27 and PTEN and with reduced recurrence-free survival. Clin Cancer Res 8: 3419-3426, 2002.

17. Traub F, Mengel M, Lück HJ, Kreipe HH and von Wasielewski R: Prognostic impact of Skp2 and p27 in human breast cancer. Breast Cancer Res Treat 99: 185-191, 2006.

18. Li JQ, Wu F, Masaki T, Kubo A, Fujita J, Dixon DA, Beauchamp RD, Ishida T, Kuriyama S and Imaida K: Correlation of Skp2 with carcinogenesis, invasion, metastasis, and prognosis in colorectal tumors. Int J Oncol 25: 87-95, 2004.

19. Hershko DD: Oncogenic properties and prognostic implications of the ubiquitin ligase Skp2 in cancer. Cancer 112: 1415-1424, 2008.

20. Inuzuka H, Gao D, Finley LW, Yang W, Wan L, Fukushima H, Chin YR, Zhai B, Shaik S, Lau AW, et al: Acetylation-dependent regulation of Skp2 function. Cell 150: 179-193, 2012. 
21. Wang Z, Inuzuka H, Zhong J, Liu P, Sarkar FH, Sun Y and Wei W: Identification of acetylation-dependent regulatory mechanisms that govern the oncogenic functions of Skp2. Oncotarget 3: 1294-1300, 2012

22. da Silva GN, de Camargo EA, Sávio AL and Salvadori DM: MRE11A and SKP2 genes are associated with the increased cytotoxicity induced by the synergistic effects of cisplatin and gemcitabine in bladder cancer cells. Mol Biol Rep 41: 4613-4621, 2014.

23. Wang J, Huang Y, Guan Z, Zhang JL, Su HK, Zhang W, Yue CF, Yan M, Guan S and Liu QQ: E3-ligase Skp2 predicts poor prognosis and maintains cancer stem cell pool in nasopharyngeal carcinoma. Oncotarget 5: 5591-5601, 2014

24. Pascal LE and Wang Z: Virtual drug design: Skp1-Skp2 inhibition targets cancer stem cells. Asian J Androl 15: 717-718, 2013.

25. Chan CH, Morrow JK, Li CF, Gao Y, Jin G, Moten A, Stagg LJ, Ladbury JE, Cai Z, Xu D, et al: Pharmacological inactivation of Skp2 SCF ubiquitin ligase restricts cancer stem cell traits and cancer progression. Cell 154: 556-568, 2013.

26. Totary-Jain H, Sanoudou D, Dautriche CN, Schneller H, Zambrana L and Marks AR: Rapamycin resistance is linked to defective regulation of Skp2. Cancer Res 72: 1836-1843, 2012.

27. Wang XC, Tian LL, Tian J and Jiang XY: Overexpression of SKP2 promotes the radiation resistance of esophageal squamous cell carcinoma. Radiat Res 177: 52-58, 2012.

28. Masuda TA, Inoue H, Sonoda H, Mine S, Yoshikawa Y, Nakayama K, Nakayama K and Mori M: Clinical and biological significance of S-phase kinase-associated protein 2 (Skp2) gene expression in gastric carcinoma: Modulation of malignant phenotype by Skp2 overexpression, possibly via p27 proteolysis. Cancer Res 62: 3819-3825, 2002.

29. Ma XM, Liu Y, Guo JW, Liu JH and Zuo LF: Relation of overexpression of $\mathrm{S}$ phase kinase-associated protein 2 with reduced expression of p27 and PTEN in human gastric carcinoma. World J Gastroenterol 11: 6716-6721, 2005.

30. Honjo S, Kase S, Osaki M, Ardyanto TD, Kaibara N and Ito $\mathrm{H}$ : COX-2 correlates with F-box protein, Skp2 expression and prognosis in human gastric carcinoma. Int J Oncol 26: 353-360, 2005.

31. Yan LH, Wang XT, Yang J, Kong FB, Lian C, Wei WY, Luo W, Xie YB and Xiao Q: Reversal of multidrug resistance in gastric cancer cells by E2F-1 downregulation in vitro and in vivo. J Cell Biochem 115: 34-41, 2014.

32. Trimarchi JM and Lees JA: Sibling rivalry in the E2F family. Nat Rev Mol Cell Biol 3: 11-20, 2002.

33. Wei Z, Jiang X, Liu F, Qiao H, Zhou B, Zhai B, Zhang L, Zhang X, Han L, Jiang H, et al: Downregulation of Skp2 inhibits the growth and metastasis of gastric cancer cells in vitro and in vivo. Tumour Biol 34: 181-192, 2013.

34. Eguchi H, Herschenhous N, Kuzushita N and Moss SF: Helicobacter pylori increases proteasome-mediated degradation of p27(kip1) in gastric epithelial cells. Cancer Res 63: 4739-4746, 2003

35. Kim SS, Meitner P, Konkin TA, Cho YS, Resnick MB and Moss SF: Altered expression of Skp2, c-Myc and p27 proteins but not mRNA after $H$. pylori eradication in chronic gastritis. Mod Pathol 19: 49-58, 2006.

36. Kim SS, Cho YS, Kim HK, Shin OR, Chae HS, Choi MG and Chung IS: The effect of rosiglitazone on the cell proliferation and the expressions of p27 and skp2 in helicobacter pylori infected human gastric epithelial cells. Korean J Gastroenterol 55: 225-231, 2010 (In Korean).

37. Skaar JR, Pagan JK and Pagano M: Mechanisms and function of substrate recruitment by F-box proteins. Nat Rev Mol Cell Biol 14: 369-381, 2013

38. Yoshida Y, Chiba T, Tokunaga F, Kawasaki H, Iwai K, Suzuki T, Ito Y, Matsuoka K, Yoshida M, Tanaka K, et al: E3 ubiquitin ligase that recognizes sugar chains. Nature 418: 438-442, 2002.

39. Yoshida Y, Tokunaga F, Chiba T, Iwai K, Tanaka K and Tai T: Fbs2 is a new member of the E3 ubiquitin ligase family that recognizes sugar chains. J Biol Chem 278: 43877-43884, 2003.

40. Janoueix-Lerosey I, Novikov E, Monteiro M, Gruel N, Schleiermacher G, Loriod B, Nguyen C and Delattre O: Gene expression profiling of 1p35-36 genes in neuroblastoma. Oncogene 23: 5912-5922, 2004

41. Merry C, Fu K, Wang J, Yeh IJ and Zhang Y: Targeting the checkpoint kinase Chk1 in cancer therapy. Cell Cycle 9: 279-283, 2010.

42. Zhang YW, Brognard J, Coughlin C, You Z, Dolled-Filhart M, Aslanian A, Manning G, Abraham RT and Hunter T: The F box protein Fbx6 regulates Chk1 stability and cellular sensitivity to replication stress. Mol Cell 35: 442-453, 2009.
43. Hwang GW, Du K, Takahashi T and Naganuma A: Inhibition of F-box protein FBXO6 gene expression by RNA interference enhances cadmium toxicity in HEK293 cells. J Toxicol Sci 36: 847-849, 2011.

44. Zhang L, Hou Y, Wang M, Wu B and Li N: A study on the functions of ubiquitin metabolic system related gene FBG2 in gastric cancer cell line. J Exp Clin Cancer Res 28: 78, 2009.

45. Gomes MD, Lecker SH, Jagoe RT, Navon A and Goldberg AL: Atrogin-1, a muscle-specific F-box protein highly expressed during muscle atrophy. Proc Natl Acad Sci USA 98: 14440-14445, 2001.

46. Mastrocola R, Reffo P, Penna F, Tomasinelli CE, Boccuzzi G, Baccino FM, Aragno M and Costelli P: Muscle wasting in diabetic and in tumor-bearing rats: Role of oxidative stress. Free Radic Biol Med 44: 584-593, 2008.

47. Costelli P, Muscaritoli M, Bossola M, Penna F, Reffo P, Bonetto A, Busquets S, Bonelli G, Lopez-Soriano FJ, Doglietto GB, et al: IGF-1 is downregulated in experimental cancer cachexia. Am J Physiol Regul Integr Comp Physiol 291: R674-R683, 2006.

48. D'Orlando C, Marzetti E, François S, Lorenzi M, Conti V, di Stasio E, Rosa F, Brunelli S, Doglietto GB, Pacelli F, et al: Gastric cancer does not affect the expression of atrophy-related genes in human skeletal muscle. Muscle Nerve 49: 528-533, 2014.

49. Bonetto A, Penna F, Aversa Z, Mercantini P, Baccino FM, Costelli P, Ziparo V, Lucia S, Rossi Fanelli F and Muscaritoli M: Early changes of muscle insulin-like growth factor-1 and myostatin gene expression in gastric cancer patients. Muscle Nerve 48: 387-392, 2013.

50. Zou Z, Anisowicz A, Hendrix MJ, Thor A, Neveu M, Sheng S, Rafidi K, Seftor E and Sager R: Maspin, a serpin with tumorsuppressing activity in human mammary epithelial cells. Science 263: 526-529, 1994

51. Lei KF, Liu BY, Wang YF, Chen XH, Yu BQ, Guo Y and Zhu ZG: SerpinB5 interacts with KHDRBS3 and FBXO32 in gastric cancer cells. Oncol Rep 26: 1115-1120, 2011.

52. Hartwell LH, Mortimer RK, Culotti J and Culotti M: Genetic control of the cell division cycle in yeast: V. Genetic analysis of cdc mutants. Genetics 74: 267-286, 1973.

53. Sionov RV, Netzer E and Shaulian E: Differential regulation of FBXW7 isoforms by various stress stimuli. Cell Cycle 12: $3547-3554,2013$

54. Crusio KM, King B, Reavie LB and Aifantis I: The ubiquitous nature of cancer: The role of the SCF(Fbw7) complex in development and transformation. Oncogene 29: 4865-4873, 2010.

55. Matsumoto A, Onoyama I and Nakayama KI: Expression of mouse Fbxw7 isoforms is regulated in a cell cycle- or p53-dependent manner. Biochem Biophys Res Commun 350: 114-119, 2006.

56. Welcker M, Orian A, Grim JE, Eisenman RN and Clurman BE: A nucleolar isoform of the Fbw7 ubiquitin ligase regulates c-Myc and cell size. Curr Biol 14: 1852-1857, 2004

57. Minella AC, Welcker M and Clurman BE: Ras activity regulates cyclin E degradation by the Fbw7 pathway. Proc Natl Acad Sci USA 102: 9649-9654, 2005.

58. Yada M, Hatakeyama S, Kamura T, Nishiyama M, Tsunematsu R, Imaki H, Ishida N, Okumura F, Nakayama K and Nakayama KI: Phosphorylation-dependent degradation of c-Myc is mediated by the F-box protein Fbw7. EMBO J 23: 2116-2125, 2004.

59. Hoeck JD, Jandke A, Blake SM, Nye E, Spencer-Dene B, Brandner S and Behrens A: Fbw7 controls neural stem cell differentiation and progenitor apoptosis via Notch and c-Jun. Nat Neurosci 13: 1365-1372, 2010.

60. Rocher-Ros V, Marco S, Mao JH, Gines S, Metzger D, Chambon P, Balmain A and Saura CA: Presenilin modulates EGFR signaling and cell transformation by regulating the ubiquitin ligase Fbw7. Oncogene 29: 2950-2961, 2010.

61. Inuzuka H, Shaik S, Onoyama I, Gao D, Tseng A, Maser RS, Zhai B, Wan L, Gutierrez A, Lau AW, et al: SCF(FBW7) regulates cellular apoptosis by targeting MCL1 for ubiquitylation and destruction. Nature 471: 104-109, 2011.

62. Tan M, Zhao Y, Kim SJ, Liu M, Jia L, Saunders TL, Zhu Y and Sun Y: SAG/RBX2/ROC2 E3 ubiquitin ligase is essential for vascular and neural development by targeting NF1 for degradation. Dev Cell 21: 1062-1076, 2011

63. Fukushima H, Matsumoto A, Inuzuka H, Zhai B, Lau AW, Wan L, Gao D, Shaik S, Yuan M, Gygi SP, et al: SCF(Fbw7) modulates the NFKB signaling pathway by targeting NFKB2 for ubiquitination and destruction. Cell Rep 1: 434-443, 2012.

64. Busino L, Millman SE, Scotto L, Kyratsous CA, Basrur V, O'Connor O, Hoffmann A, Elenitoba-Johnson KS and Pagano M: Fbxw $7 \alpha$ - and GSK3-mediated degradation of p100 is a prosurvival mechanism in multiple myeloma. Nat Cell Biol 14: 375-385, 2012. 
65. Lochab S, Pal P, Kapoor I, Kanaujiya JK, Sanyal S, Behre G and Trivedi AK: E3 ubiquitin ligase Fbw7 negatively regulates granulocytic differentiation by targeting G-CSFR for degradation. Biochim Biophys Acta 1833: 2639-2652, 2013.

66. Tu K, Yang W, Li C, Zheng X, Lu Z, Guo C, Yao Y and Liu Q: Fbxw7 is an independent prognostic marker and induces apoptosis and growth arrest by regulating YAP abundance in hepatocellular carcinoma. Mol Cancer 13: 110, 2014.

67. Huhn S, Bevier M, Pardini B, Naccarati A, Vodickova L, Novotny J, Vodicka P, Hemminki K and Försti A: Colorectal cancer risk and patients' survival: Influence of polymorphisms in genes somatically mutated in colorectal tumors. Cancer Causes Control 25: 759-769, 2014.

68. Brim H, Abu-Asab MS, Nouraie M, Salazar J, Deleo J, Razjouyan H, Mokarram P, Schaffer AA, Naghibhossaini F and Ashktorab $\mathrm{H}$ : An integrative $\mathrm{CGH}$, MSI and candidate genes methylation analysis of colorectal tumors. PLoS One 9: e82185, 2014.

69. Babaei-Jadidi R, Li N, Saadeddin A, Spencer-Dene B, Jandke A, Muhammad B, Ibrahim EE, Muraleedharan R, Abuzinadah M, Davis $\mathrm{H}$, et al: FBXW7 influences murine intestinal homeostasis and cancer, targeting Notch, Jun, and DEK for degradation. J Exp Med 208: 295-312, 2011.

70. Davis H, Lewis A, Behrens A and Tomlinson I: Investigation of the atypical FBXW7 mutation spectrum in human tumours by conditional expression of a heterozygous propellor tip missense allele in the mouse intestines. Gut 63: 792-799, 2014.

71. Grim JE, Knoblaugh SE, Guthrie KA, Hagar A, Swanger J, Hespelt J, Delrow JJ, Small T, Grady WM, Nakayama KI, et al: Fbw7 and p53 cooperatively suppress advanced and chromosomally unstable intestinal cancer. Mol Cell Biol 32: 2160-2167, 2012.

72. Milne AN, Leguit R, Corver WE, Morsink FH, Polak M, de Leng WW, Carvalho R and Offerhaus GJ: Loss of CDC4/ FBXW7 in gastric carcinoma. Cell Oncol 32: 347-359, 2010.

73. Yokobori T, Mimori K, Iwatsuki M, Ishii H, Onoyama I, Fukagawa T, Kuwano H, Nakayama KI and Mori M: p53-altered FBXW7 expression determines poor prognosis in gastric cancer cases. Cancer Res 69: 3788-3794, 2009.

74. Li J, Guo Y, Liang X, Sun M, Wang G, De W and Wu W: MicroRNA-223 functions as an oncogene in human gastric cancer by targeting FBXW7/hCdc4. J Cancer Res Clin Oncol 138: 763-774, 2012.

75. Eto K, Iwatsuki M, Watanabe M, Ishimoto T, Ida S, Imamura Y, Iwagami S, Baba Y, Sakamoto Y, Miyamoto Y, et al: The sensitivity of gastric cancer to trastuzumab is regulated by the miR-223/FBXW7 pathway. Int J Cancer 136: 1537-1545, 2015.

76. Shirane M, Hatakeyama S, Hattori K, Nakayama K and Nakayama K: Common pathway for the ubiquitination of IkappaBalpha, IkappaBbeta, and IkappaBepsilon mediated by the F-box protein FWD1. J Biol Chem 274: 28169-28174, 1999.

77. Spiegelman VS, Slaga TJ, Pagano M, Minamoto T, Ronai Z and Fuchs SY: Wnt/beta-catenin signaling induces the expression and activity of betaTrCP ubiquitin ligase receptor. Mol Cell 5: $877-882,2000$

78. Zhang N, Wei P, Gong A, Chiu WT, Lee HT, Colman H, Huang H, Xue J, Liu M, Wang Y, et al: FoxM1 promotes $\beta$-catenin nuclear localization and controls Wnt target-gene expression and glioma tumorigenesis. Cancer Cell 20: 427-442, 2011.

79. Mokkapati S, Niopek K, Huang L, Cunniff KJ, Ruteshouser EC, deCaestecker M, Finegold MJ and Huff V: $\beta$-catenin activation in a novel liver progenitor cell type is sufficient to cause hepatocellular carcinoma and hepatoblastoma. Cancer Res 74 4515-4525, 2014.
80. Wu Y, Deng J, Rychahou PG, Qiu S, Evers BM and Zhou BP: Stabilization of snail by NF-kappaB is required for inflammationinduced cell migration and invasion. Cancer Cell 15: 416-428, 2009.

81. Saitoh T and Katoh M: Expression profiles of betaTRCP1 and betaTRCP 2 , and mutation analysis of betaTRCP 2 in gastric cancer. Int J Oncol 18: 959-964, 2001.

82. Kim CJ, Song JH, Cho YG, Kim YS, Kim SY, Nam SW, Yoo NJ, Lee JY and Park WS: Somatic mutations of the beta-TrCP gene in gastric cancer. APMIS 115: 127-133, 2007.

83. Vashisht AA, Zumbrennen KB, Huang X, Powers DN, Durazo A, Sun D, Bhaskaran N, Persson A, Uhlen M, Sangfelt O, et al: Control of iron homeostasis by an iron-regulated ubiquitin ligase. Science 326: 718-721, 2009.

84. Salahudeen AA, Thompson JW, Ruiz JC, Ma HW, Kinch LN Li Q, Grishin NV and Bruick RK: An E3 ligase possessing an iron-responsive hemerythrin domain is a regulator of iron homeostasis. Science 326: 722-726, 2009.

85. Moroishi T, Nishiyama M, Takeda Y, Iwai K and Nakayama KI: The FBXL5-IRP2 axis is integral to control of iron metabolism in vivo. Cell Metab 14: 339-351, 2011.

86. Dragoi AM, Swiss R, Gao B and Agaisse H: Novel strategies to enforce an epithelial phenotype in mesenchymal cells. Cancer Res 74: 3659-3672, 2014.

87. Chen ZW, Liu B, Tang NW, Xu YH, Ye XY, Li ZM, Niu XM, Shen SP, Lu S and Xu L: FBXL5-mediated degradation of singlestranded DNA-binding protein hSSB1 controls DNA damage response. Nucleic Acids Res 42: 11560-11569, 2014.

88. Cen G, Ding HH, Liu B and Wu WD: FBXL5 targets cortactin for ubiquitination-mediated destruction to regulate gastric cancer cell migration. Tumour Biol 35: 8633-8638, 2014.

89. Wu H and Parsons JT: Cortactin, an 80/85-kilodalton pp60src substrate, is a filamentous actin-binding protein enriched in the cell cortex. J Cell Biol 120: 1417-1426, 1993.

90. MacGrath SM and Koleske AJ: Cortactin in cell migration and cancer at a glance. J Cell Sci 125: 1621-1626, 2012.

91. Santra MK, Wajapeyee N and Green MR: F-box protein FBXO31 mediates cyclin D1 degradation to induce G1 arrest after DNA damage. Nature 459: 722-725, 2009.

92. Jia L and Sun Y: F-box proteins FBXO31 and FBX4 in regulation of cyclin D1 degradation upon DNA damage. Pigment Cell Melanoma Res 22: 518-519, 2009.

93. Vadhvani M, Schwedhelm-Domeyer N, Mukherjee C and Stegmüller J: The centrosomal E3 ubiquitin ligase FBXO31-SCF regulates neuronal morphogenesis and migration. PLoS One 8: e57530, 2013

94. Huang HL, Zheng WL, Zhao R, Zhang B and Ma WL: FBXO31 is down-regulated and may function as a tumor suppressor in hepatocellular carcinoma. Oncol Rep 24: 715-720, 2010

95. Kogo R, Mimori K, Tanaka F, Komune S and Mori M: FBXO31 determines poor prognosis in esophageal squamous cell carcinoma. Int J Oncol 39: 155-159, 2011.

96. Zhang X, Kong Y, Xu X, Xing H, Zhang Y, Han F, Li W, Yang Q, Zeng J, Jia J, et al: F-box protein FBXO31 is down-regulated in gastric cancer and negatively regulated by miR-17 and miR-20a. Oncotarget 5: 6178-6190, 2014.

97. Kumar R, Neilsen PM, Crawford J, McKirdy R, Lee J, Powell JA, Saif Z, Martin JM, Lombaerts M, Cornelisse CJ, et al: FBXO31 is the chromosome 16q24.3 senescence gene, a candidate breast tumor suppressor, and a component of an SCF complex. Cancer Res 65: 11304-11313, 2005. 